\title{
REFLEXÕES SOBRE O USO DE AGROTÓXICOS E SUAS CONSEQUÊNCIAS
}

\author{
Bianca Alves Lima Ribeiro \\ Graduanda em Ciências Biológicas - Universidade do Estado do Rio de Janeiro UERJ- OUERJ/ ONU/ \\ UN-Habitat \\ $\triangle$ biancalima.bio@gmail.com
}

\begin{abstract}
Thereza Cristina Ferreira Camello
Biomédica - Doutora em Ciências Médicas - Microbiologista - Hospital Universitário Pedro Ernesto Universidade do Estado do Rio de Janeiro - UERJ/ OUERJ/ ONU/ UN-Habitat
\end{abstract}

\begin{abstract}
Resumo:
Este trabalho visou compilar uma vasta gama de dados secundários obtidos de fontes confiáveis, a fim de apresentar uma visão holística sobre o uso dos agrotóxicos na alimentação e as possíveis consequências oriundas deste processo. Para fins didáticos, o texto foi subdividido em alguns itens, como: disposições legais, que caracteriza o cenário legal brasileiro no que tange o uso de agrotóxicos; impacto na biodiversidade, no qual discute-se as alterações no ambiente e impacto na saúde humana, onde explana-se sobre as possíveis consequências no âmbito da saúde coletiva quanto a ingestão e/ ou contato com agrotóxicos.

Palavras-chave: agrotóxicos, saúde coletiva, agricultura.

\section{REFLEXIONS ON THE USE OF PESTICIDES AND THEIR POSSIBLE CONSEQUENCES}

\section{Abstract:}

This study aimed to compile a wide range of secondary data obtained from reliable sources, in order to present a holistic view on the use of pesticides in food and the possible consequences arising from this process. For didactic purposes, the text was divided into some items such as: legal, featuring the Brazilian legal scenario regarding the use of pesticides; impact on biodiversity, which discusses the changes in the environment and impact on human health, where it explains about the possible consequences in the context of public health and the ingestion and / or contact with pesticides.

Keywords: agrochemicals, public health, agriculture.

\section{INTRODUÇÃO}

O processo produtivo agrícola brasileiro está cada vez mais dependente dos agrotóxicos e fertilizantes químicos. A lei dos agrotóxicos, de 1989, e o decreto que a regulamenta, de 2002, definem que essas substâncias são:

“Os produtos e os agentes de processos físicos, químicos ou biológicos, destinados ao uso nos setores de produção, no armazenamento e beneficiamento de produtos agrícolas, nas pastagens, na proteção de florestas, nativas ou implantadas, e de outros ecossistemas e também de ambientes urbanos, hídricos e industriais, cuja finalidade seja alterar a composição da flora ou da fauna, a fim de preservá-las da ação danosa de seres vivos considerados nocivos" (CARNEIRO et al., 2012). 
Segundo a atual legislação, compete ao Ministério da Agricultura, Pecuária e Abastecimento realizar a variação de eficácia agronômica, ao Ministério da Saúde de executar a avaliação e classificação Toxicológica e ao Ministério do Meio Ambiente avaliar e classificar o potencial de periculosidade ambiental (PERES e MOREIRA, 2003). Já que os impactos gerados pelo uso destas substâncias variam de acordo com as propriedades físicoquímicas dos produtos, bem como seu modo de aplicação. O tipo de ambiente com o qual o agrotóxico interage também é determinante para a mensuração da magnitude e gravidade de seu impacto na saúde humana e ambiental. Com isso, espera-se minimizar os riscos de manipulação e ingestão desses compostos químicos.

De acordo com o Ministério do Meio Ambiente, os agrotóxicos podem ser divididos em duas categorias:

1. Agrícolas: destinados ao uso nos setores de produção, no armazenamento e beneficiamento de produtos agrícolas, nas pastagens e nas florestas plantadas - cujos registros são concedidos pelo Ministério da Agricultura, Pecuária e Abastecimento, atendidas as diretrizes e exigências dos Ministérios da Saúde e do Meio Ambiente.

2. Não - agrícolas: destinados ao uso na proteção de florestas nativas, outros ecossistemas ou de ambientes hídricos - cujos registros são concedidos pelo Ministério do Meio Ambiente/ IBAMA, atendidas as diretrizes e exigências dos Ministérios da Agricultura, Pecuária e Abastecimento e da Saúde.

- destinados ao uso em ambientes urbanos e industriais, domiciliares, públicos ou coletivos, ao tratamento de água e ao uso em campanhas de saúde pública - cujos registros são concedidos pelo Ministério da Saúde/ ANVISA, atendidas as diretrizes e exigências dos Ministérios da Agricultura e do Meio Ambiente.

\section{Disposições Legais ou Legislação atual}

A lei 7802/89, dispõe sobre a pesquisa, a experimentação, a produção, a embalagem e rotulagem, o transporte, o armazenamento, a comercialização, a propaganda comercial, a utilização, a importação, a exportação, o destino final dos resíduos e embalagens, o registro, a classificação, o controle, a inspeção e a fiscalização de agrotóxicos, seus componentes e afins, e dá outras providências. 
Para a aprovação de uma nova substância química na agricultura, é necessário que ela solicite o registro ao MAPA, ANVISA e IBAMA. Cada um desses órgãos fará respectivamente: um dossiê agronômico, toxicológico, ambiental. Após essa etapa, há um resultado convergente do pleito, como mostra a figura 1.

Figura 1. Esquema do procedimento de aprovação de uma nova substância.

(ANVISA)

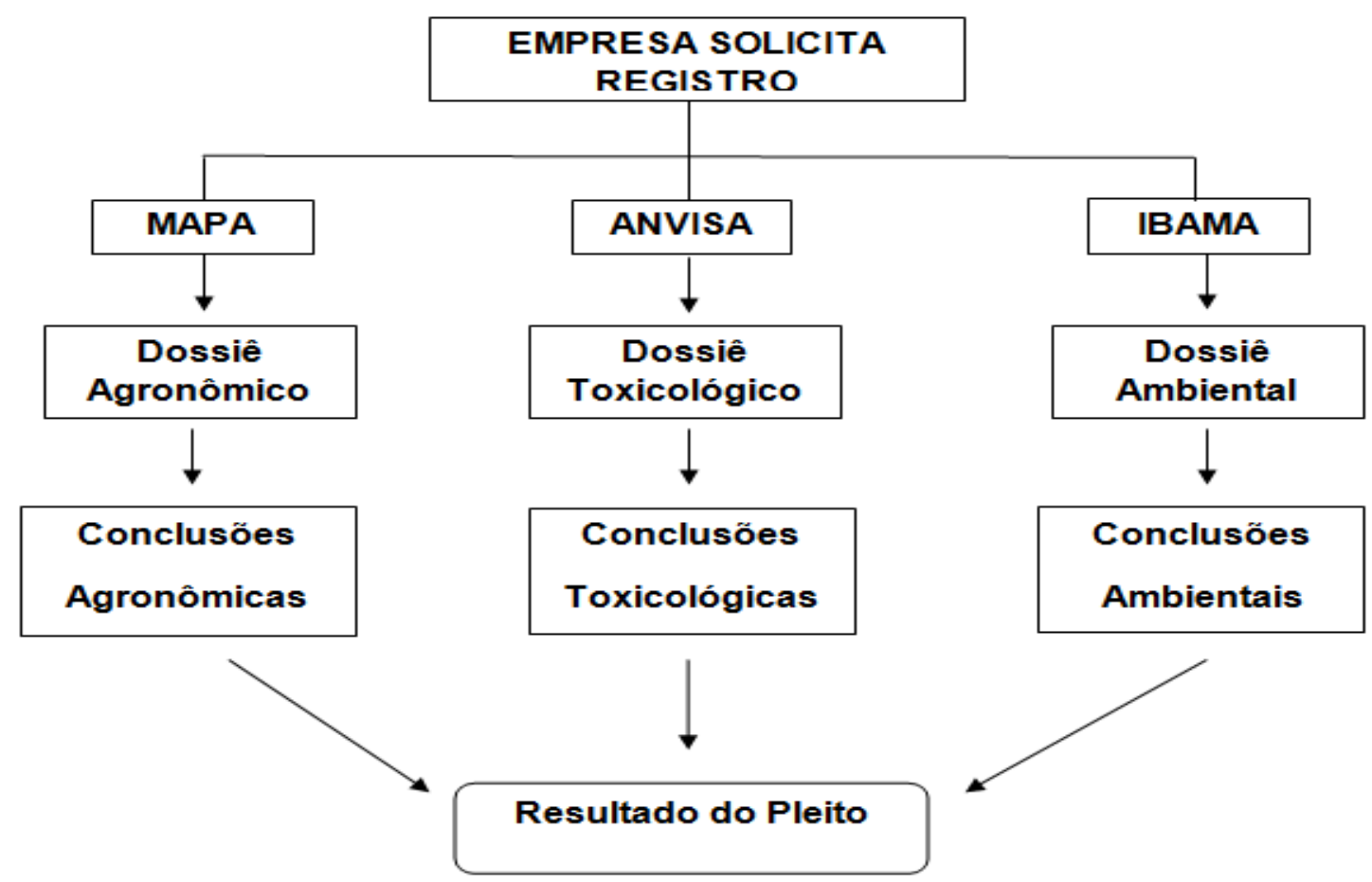

Fonte: Carlos Alexandre Oliveira Gomes $48^{\circ}$ Congresso Brasileiro de Olericultura (adaptado) 
Figura 2. Amostras analisadas por cultura e resultados insatisfatórios 2011 (ANVISA)

\begin{tabular}{|c|c|c|c|c|c|c|c|c|c|}
\hline \multirow[t]{2}{*}{ Produto } & \multirow[t]{2}{*}{$\begin{array}{c}\text { № de amostras } \\
\text { analisadas }\end{array}$} & \multicolumn{2}{|c|}{$\begin{array}{c}\begin{array}{c}\text { Agrotóxico não } \\
\text { autorizado }\end{array} \\
\text { (1) }\end{array}$} & \multicolumn{2}{|c|}{$\begin{array}{l}\text { Acima do limite } \\
\text { (2) }\end{array}$} & \multicolumn{2}{|c|}{$\begin{array}{c}\begin{array}{c}\text { Acima do limite e } \\
\text { não autorizado }\end{array} \\
\text { (3) }\end{array}$} & \multicolumn{2}{|c|}{$\begin{array}{c}\begin{array}{c}\text { Total de } \\
\text { Insatisfatórios }\end{array} \\
(1+2+3)\end{array}$} \\
\hline & & № & $\%$ & № & $\%$ & № & $\%$ & № & $\%$ \\
\hline Alface & 134 & 55 & $41 \%$ & 1 & $0,7 \%$ & 2 & $1,5 \%$ & 58 & $43 \%$ \\
\hline Arroz & 162 & 26 & $16 \%$ & 0 & $0,0 \%$ & 0 & $0,0 \%$ & 26 & $16 \%$ \\
\hline Cenoura & 152 & 102 & $67 \%$ & 0 & $0,0 \%$ & 0 & $0,0 \%$ & 102 & $67 \%$ \\
\hline Feijão & 217 & 13 & $6 \%$ & 0 & $0,0 \%$ & 0 & $0,0 \%$ & 13 & $6 \%$ \\
\hline Mamão & 191 & 20 & $10 \%$ & 14 & $7,3 \%$ & 4 & $2,1 \%$ & 38 & $20 \%$ \\
\hline Pepino & 200 & 71 & $36 \%$ & 10 & $5,0 \%$ & 7 & $3,5 \%$ & 88 & $44 \%$ \\
\hline Pimentão & 213 & 178 & $84 \%$ & 2 & $0,9 \%$ & 10 & $4,7 \%$ & 190 & $89 \%$ \\
\hline Tomate & 151 & 14 & $9 \%$ & 0 & $0,0 \%$ & 4 & $2,6 \%$ & 18 & $12 \%$ \\
\hline Uva & 208 & 41 & $20 \%$ & 11 & $5,3 \%$ & 4 & $1,9 \%$ & 56 & $27 \%$ \\
\hline TOTAL & 1.628 & 520 & $32 \%$ & 38 & $2,3 \%$ & 31 & $1,9 \%$ & 589 & $36 \%$ \\
\hline
\end{tabular}

LEGENDA: (1) amostras que apresentaram somente IA não autorizados (NA); (2) amostras somente com ingredientes ativos autorizados, mas acima dos limites máximos autorizados (> LMR); (3) amostras com as duas irregularidades (NA e > LMR); $(1+2+3)$ soma de todos os tipos de irregularidades.

FONTE: Carneiro, F F et al. DOSSIÊ ABRASCO, 2012- Um alerta sobre os impactos dos agrotóxicos na saúde. DOSSIÊ ABRASCO, 2012, Rio de Janeiro, 2012.

\section{Panorama geral sobre a utilização de agrotóxicos no Brasil e no mundo.}

Há certo consenso científico de que seu uso inadequado pode ocasionar nos seres humanos efeitos de caráter agudo, resultado de uma exposição direta a uma única dose do produto, provocando uma morte rápida, ou lenta, através da acumulação gradativa de toxicidade no organismo. Os efeitos podem abranger diversos tipos de câncer, defeitos de nascimento, mudanças genéticas que podem passar a outras gerações, doenças nervosas, alterações do sistema imunológico, lesões hepáticas, lesões renais, atrofia testicular, etc. (COYE, 1986; HAYES e LAWS, 1991). Alguns cientistas consideram que para certos perigos, como o câncer, qualquer nível de exposição pode ser de risco, não existindo a possibilidade de definir uma separação entre níveis seguros e inseguros de exposição (MOTT e SNYDER, 1987). 
Cerca de 434 ingredientes ativos (IA) e 2.400 formulações de agrotóxicos estão registrados no Ministério da Saúde (MS), MAPA e Ministério do Meio Ambiente (MMA) e são permitidos no Brasil de acordo com os critérios de uso e indicação estabelecidos em suas Monografias. Porem, dos 50 mais utilizados nas lavouras de nosso pais, 22 são proibidos na União Europeia. Na Anvisa estao em processo de revisão, desde 2008, 14 agrotóxicos: quatro deles ja foram proibidos (cihexatina e tricloform), sendo que o metamidofos será retirado do mercado a partir de junho de 2012 e o endossulfam a partir de junho de 2013 . O fosmete e o acefato tiveram seus usos restringidos, apesar dos achados toxicológicos serem indicativos de banimento. Outros dois ja concluíram a consulta publica de revisão (forato e parationametilica) e os demais já tiveram suas notas técnicas de revisão concluídas: lactofem, furano, tiram, paraquat, glifosato, abamectina (ANVISA, 2008; 2012a; 2012b).

Em relação as hortaliças, com base em dados disponíveis na literatura especializada, o consumo de fungicidas atingiu uma área potencial de aproximadamente 800 mil hectares, contra 21 milhões de hectares somente na cultura da soja. Isso revela um quadro preocupante de concentração no uso de ingrediente ativo de fungicida por área plantada em hortaliças no Brasil, podendo chegar entre 8 a 16 vezes mais agrotóxico por hectare do que o utilizado na cultura da soja, por exemplo. Numa comparação simples, estima-se que a concentração de uso de ingrediente ativo de fungicida em soja no Brasil, no ano de 2008, foi de 0,5 litro por hectare, bem inferior a estimativa de quatro a oito litros por hectare em hortaliças, em media. Pode-se constatar que cerca de $20 \%$ da comercialização de ingrediente ativo de fungicida no Brasil e destinada ao uso em hortaliças. Dessa maneira pode-se inferir que o uso de agrotóxicos em hortaliças, especialmente de fungicidas, expõe de forma perigosa e frequente o consumidor, o ambiente e os trabalhadores a contaminação química por uso de agrotóxicos (ALMEIDA et al., 2009).

Os efeitos sobre a saúde podem ser de dois tipos: 1) efeitos agudos, ou aqueles que resultam da exposição a concentrações de um ou mais agentes tóxicos, capazes de causar dano efetivo aparente em um período de 24 horas; 2) efeitos crônicos, ou aqueles que resultam de uma exposição continuada a doses relativamente baixas de um ou mais produtos. (RIBAS et al, 2009).

Se surgem casos de intoxicações, contaminações, ou se encontram resíduos tóxicos de pesticidas nos alimentos, a responsabilidade passa a ser de quem? Não é preciso pensar duas vezes a resposta. Os parâmetros estabelecidos cientificamente servem, em muitos casos, para acabar atribuindo a culpa dos problemas de contaminação ou intoxicação não aos cientistas, 
nem ao Estado, nem as empresas, mas aos próprios agricultores, que estariam utilizando de forma "inadequada" o insumo, por falta de conhecimento, por negligência ou por irracionalidade, ocasionando "acidentes". Este argumento é o outro lado do consenso científico sobre os riscos, que encontra um terreno propício para ser aceito na alta divisão do trabalho, entre pesquisa, produção difusão, venda e uso de agrotóxicos, que provoca a diluição social dos efeitos, sem que a responsabilidade pelos problemas seja assumida por alguém mais que os agricultores. (GUIVANT, 2000)

\section{Impacto na biodiversidade}

Calcula-se que aproximadamente 500 espécies de pragas, $60 \%$ das quais são perigosas para a agricultura, têm desenvolvido resistências genéticas devido à exposição repetida a pesticidas. Só entre 1970 e 1980 considera-se que quase dobrou o número de insetos resistentes aos inseticidas. Isto tem levado ao aumento das dosagens dos agrotóxicos aplicados nas lavouras, mas sem que por isto tenha-se evitado que as perdas de colheitas por pragas quase tenham dobrado desde os anos 40 (MOTT e SNYDER, 1987; BARROW, 1995).

Um sistema de produção agrícola por si só já reduz a diversidade biológica do ambiente a partir da transformação de um ecossistema em um agrossistema. Esse desequilíbrio é quase que completo quando se trata de monoculturas, que são agrossistemas extremamente simplificados e, portanto, mais suscetíveis ao aparecimento de espécies nocivas à cultura plantada. (SOARES, 2010)

O problema passa a ser ainda pior quando há o uso intensivo desses insumos, pois os agrotóxicos, além de erradicarem as pragas, também eliminariam seus inimigos naturais, ou seja, seus predadores e competidores. Acrescenta-se o fato do aumento de resistência por parte das pragas, que passam a tolerar doses que antes matavam quase a totalidade de seus progenitores (PASCHOAL, 1979).

O crescimento do uso desses insumos químicos somados a um processo de desenvolvimento e difusão de variedades modernas com elevada capacidade de aproveitamento desses produtos ficou conhecido como a "revolução verde" (BULL e HATHAWAY, 1986).

\section{Impacto na saúde humana}

Mesmo que alguns dos ingredientes ativos dos agrotóxicos, por seus efeitos agudos, possam ser classificados como medianamente ou pouco tóxicos, não se pode perder de vista os efeitos crônicos que podem ocorrer meses, anos ou até décadas após a exposição, 
manifestando-se em varias doenças como cânceres, má formação congênita, distúrbios endócrinos, neurológicos e mentais. (CARNEIRO et al., 2012).

Figura 3. Classificação dos agrotóxicos e consequências de seu uso.

\begin{tabular}{|c|c|c|c|}
\hline $\begin{array}{l}\text { Cl.ASSIFICAÇÃo } \\
\text { QUANTO À PRAGA } \\
\text { QUE CONTROLA }\end{array}$ & $\begin{array}{c}\text { Classificação } \\
\text { QUanto ao GRUPo } \\
\text { QUímico }\end{array}$ & $\begin{array}{l}\text { SINTOMAS DE } \\
\text { INTOXICAÇÃo } \\
\text { AGUDA }\end{array}$ & $\begin{array}{l}\text { SINTOMAS DE } \\
\text { INTOXICAÇÃo } \\
\text { CRÔNICA }\end{array}$ \\
\hline \multirow{3}{*}{ Inseticidas } & $\begin{array}{l}\text { Organofosforados } \\
\text { e carbamatos }\end{array}$ & $\begin{array}{l}\text { Fraqueza, cólicas } \\
\text { abdominais, vômitos, } \\
\text { espasmos musculares e } \\
\text { convulsões }\end{array}$ & $\begin{array}{l}\text { Efeitos neurotóxicos } \\
\text { retardados, alteraçōes } \\
\text { cromossomiais e dermatites } \\
\text { de contato }\end{array}$ \\
\hline & Organodlorados & $\begin{array}{l}\text { Náuseas, vômitos, } \\
\text { contraçōes musculares } \\
\text { involuntárias }\end{array}$ & $\begin{array}{l}\text { Lesões hepáticas, arritmias } \\
\text { cardíacas, lesões renais e } \\
\text { neuropatias periféricas }\end{array}$ \\
\hline & Piretroides sintéticos & $\begin{array}{l}\text { Irritações das conjuntivas, } \\
\text { espirros, excitação, con- } \\
\text { vulsões }\end{array}$ & $\begin{array}{l}\text { Alergias, asma brônquica, } \\
\text { irritações nas mucosas, } \\
\text { hipersensibilidade }\end{array}$ \\
\hline \multirow[t]{2}{*}{ Fungicidas } & Ditiocarbamatos & $\begin{array}{l}\text { Tonteiras, vômitos, trem- } \\
\text { ores musculares, dor de } \\
\text { cabeça }\end{array}$ & $\begin{array}{l}\text { Alergias respiratórias, der- } \\
\text { matites, Doença de Parkin- } \\
\text { son, cânceres }\end{array}$ \\
\hline & Fentalamidas & - & Teratogeneses \\
\hline \multirow{3}{*}{ Herbicidas } & $\begin{array}{l}\text { Dinitroferóis e } \\
\text { pentaciclorofenol }\end{array}$ & $\begin{array}{l}\text { Dificuldade respiratória, } \\
\text { hipertermia, convulsōes }\end{array}$ & $\begin{array}{l}\text { Cânceres (PCP-formação de } \\
\text { dioxinas), cloroacnes }\end{array}$ \\
\hline & Fenoxiacéticos & $\begin{array}{l}\text { Perda de apetite, enjoo, } \\
\text { vômitos, fasciculação } \\
\text { muscular }\end{array}$ & $\begin{array}{l}\text { Indução da produção de } \\
\text { enzimas hepáticas, cânceres, } \\
\text { teratogeneses }\end{array}$ \\
\hline & Dipiridilos & $\begin{array}{l}\text { Sangramento nasal, } \\
\text { fraqueza, desmaios, } \\
\text { conjuntivites }\end{array}$ & $\begin{array}{l}\text { Lesões hepáticas, dermatites } \\
\text { de contato, fibrose pulmonar }\end{array}$ \\
\hline
\end{tabular}

Fonte: Carneiro, F. F. et al. DOSSIÊ ABRASCO, 2012- Um alerta sobre os impactos dos agrotóxicos na saúde. DOSSIÊ ABRASCO, 2012, Rio de Janeiro, 2012.

\section{CONSIDERAÇÕES FINAIS}

Impulsionar debates internacionais e o enfrentamento da concentração e oligopolização do sistema alimentar mundial, com vistas a estabelecer normas e regras que disciplinem a atuação das corporações transnacionais e dos grandes agentes presentes nas cadeias agroalimentares, de forma a combater as sucessivas violações do direito humano à alimentação adequada, a exemplo da criação de barreiras contra o comércio internacional de agrotóxicos (CARNEIRO et al., 2012). Estimular a elaboração e implementação de ações relacionadas a Políticas Públicas que priorizem a modificação do atual sistema de 
agronegócios e forneça subsídios para um sistema menos agressivo, tanto ambientalmente como socialmente, como a agroecologia.

Com a qualificação do debate do controle social sobre o tema, que antes era visto na perspectiva de fiscalização e controle, foi se ampliando para a dimensão de banimento, suspensão de subsídios fiscais ate alcançar o status de criação de políticas e alternativas ao seu uso com instituição de mecanismos de produção de alimentos agrosustentáveis - agroecologia e que dialogassem com o segmento da agricultura familiar e camponesa (CARNEIRO et al, 2012).

Diante de tantas lacunas de conhecimento e de tantas vulnerabilidades, devemos perguntar: e lícito manter os agrotóxicos em uso na agricultura nesse contexto? Por que não se exige das empresas a inversão do ônus da prova? Qual o papel da universidade em desenvolver métodos que de fato avaliem os impactos negativos das tecnologias mediante as condições realistas de seu uso na sociedade e das reais condições de proteção, bem como a partir de conceitos precaucionários (ABRASCO, 2012).

\section{REFERÊNCIAS BIBLIOGRÁFICAS}

ALMEIDA, V. S.; CARNEIRO, F. F.; VILELA, N. J.. Agrotóxicos em hortaliças: segurança alimentar e nutricional riscos socioambientais e políticas públicas para a promoção da saúde. Tempus Actas de Saúde Coletiva, v.4, p.84-99, Brasília, 2009.

ARIAS, A. R. L.; BUSS, D. F. ; ALBUQUERQUE, C.; INÁCIO, A. F.; FREIRE, M. M.; EGLER, M.; MUGNAI, R.; BAPTISTA, D. F. Utilização de bioindicadores na avaliação de impacto e no monitoramento da contaminação de rios e córregos por agrotóxicos. Ciênc. saúde coletiva, vol.12, n.1, p. 61-72, Rio de Janeiro, 2007.

Bull D, HAThaWAy D. Pragas e Venenos: Agrotóxicos No Brasil e no Terceiro Mundo. Petrópolis: Vozes/OXFAM/FASE, 1986.

CAMARA, M. C. C.; COSTA, L.; MARINHO, C. L. C.; GUILAM, M. C. R.. A produção científica sobre intoxicações por agrotóxicos na região serrana do Rio de Janeiro. O Mundo da Saúde, v. 32, n. 3, p. 268-74, São Paulo, 2008.

CARNEIRO, F. F.; PIGNATI, W.; RIGOTTO, R. M.; AUGUSTO, L. G. S.. RIZOLLO, A.; MULER, N. M.; ALEXANDRE, V. P.; FRIEDRICH, K.; MELLO, M. S. C..DOSSIÊ ABRASCO, 2012- Um alerta sobre os impactos dos agrotóxicos na saúde. DOSSIÊ ABRASCO, Rio de Janeiro, 2012.

DOMINGUES, M. R.; BERNARDI, M. R.; ONO, E. Y. S.; ONO, M. A.. Agrotóxicos: risco à saúde do trabalhador rural. Rev. Semina: Ciências Biológicas e da Saúde, v. 25, p. 45-54, Londrina, 2004.

GUIVANT, J. S.. Reflexividade na sociedade de risco: conflitos entre leigos e peritos sobre agrotóxicos. Herculano, Selene (Org.), Qualidade de vida e riscos ambientais. Niteroi: Editora da UFF, 2000.

HAYES, J. W.; LAWS, E.R.. Handbook of Pesticide Toxicology. General Principles. Vol. 1. $2^{\mathrm{a}}$ ed. Academic Press. San Diego, 1991. 
MOTT, L.; SNYDer, K.. Pesticide Alert. A Guide to Pesticides in Fruits and Vegetables. San Francisco: Sierra Club Books, 1987.

PASCHOAL , A. D.. Pragas, Praguicidas e a Crise Ambiental: Problemas e Soluções. Rio de Janeiro: Fundação Getúlio Vargas, 1979.

PERES F.; MOREIRA J.S.; GUIVANTJC (Org.). É veneno ou é remédio? Agrotóxicos, saúde e ambiente. Rio de Janeiro: Editora Fiocruz; 2003.

RIBAS, P. P.; MATSUMURA, A. T. S.. A química dos agrotóxicos: impacto sobre a saúde e o ambiente. Rev. Liberato. 10, n. 14, p. 149-158, Novo Hamburgo, 2009.

SOARES, W. L. Uso dos agrotóxicos e seus impactos à saúde e ao ambiente: uma avaliação integrada entre a economia, a saúde pública, a ecologia e a agricultura. 2010. 150 f. Tese (Doutorado em Saúde Pública e Meio Ambiente) - Escola Nacional de Saúde Pública, Fundação Oswaldo Cruz, Rio de Janeiro, 2010. 